\title{
JORNALISMO E DESIGN THINKING: UMA APROXIMAÇÃO EM BUSCA DE INOVAÇÕES NO CONTEÚDO ${ }^{1}$
}

\author{
Journalism and Design Thinking: an approach in search of innovations in the \\ content
}

\section{Periodismo y Design Thinking: una aproximación en busca de innovaciones en el contenido}

\author{
Ingrid Pereira de Assis \\ Universidade Federal de Santa Catarina (UFSC) \\ E-mail:ingrid.p.assis@hotmail.com \\ Cárlida Emerim \\ Universidade Federal de Santa Catarina. \\ E-mail: carlida.emerim@ufsc.br.
}

\section{Resumo}

Este artigo tem como objetivo elaborar uma aproximação da abordagem do Design Thinking com pesquisas na área de Jornalismo, na busca de um percurso metodológico que investigue narrativas inovadoras em plataformas de redes sociais. $\mathrm{Na}$ análise piloto apresentada, foram utilizadas duas ferramentas do Design Thinking, a jornada do usuário e o mapa de empatia, para extrair, da análise do processo de consumo da notícia por parte do usuário, aferições que otimizem a produção de conteúdo para plataformas que focam na autodestruição do conteúdo, tal como as Stories do Instagram. O foco do artigo é o processo de "familiarização" entre os escopos teóricometodológicos do Design Thinking e do Jornalismo, trazendo exemplo de aplicabilidade.

Palavras-chave: Design Thinking. Jornalismo. Plataformas de redes sociais.

\begin{abstract}
This article aims to elaborate an approach between Design Thinking and Journalism's Research, looking for a methodological course that investigate innovative narratives made for social network platforms. In this initial analysis, two Design Thinking's tools were used, the user's journey and the map of empathy, to extract, of the news consume process of the users, admeasurements that optimize the production of content for platforms as Stories from Instagram. Therefore, the article's focus is the process of "familiarization" between the theoretical-methodological scopes of Design Thinking and Journalism.
\end{abstract}

Key words: Design Thinking. Journalism. Social network platform.

\footnotetext{
${ }^{1} \mathrm{O}$ presente trabalho foi realizado com apoio da Coordenação de aperfeiçoamento de Pessoal de Nível Superior - Brasil (Capes) - Código de financiamento 001.
} 


\section{Resumen}

El objetivo del artículo es elaborar una aproximación del enfoque del Design Thinking con investigaciones en el campo del Periodismo en la búsqueda de un recorrido metodológico para investigar narrativas innovadoras en plataformas de redes sociales. En el análisis piloto presentado, se utilizaron dos herramientas de Design Thinking, la jornada del usuario y el mapa de empatía, para extraer del análisis del proceso de consumo de la noticia por parte del usuario, mediciones que permitan optimizar la producción de contenido para plataformas que se centran en la autodestrucción del contenido, tal como las Stories del Instagram. El enfoque del artículo es el proceso de "familiarización" entre los ámbitos teórico-metodológicos del Design Thinking y del Periodismo, trayendo ejemplo de aplicabilidad.

Palabras clave: Design Thinking. Periodismo. Plataformas de redes sociales.

\section{INTRODUÇÃO ${ }^{2}$}

O desenvolvimento da cultura elétrica (BURKE, 2008), marcado por diferentes estágios (delimitados pela ascensão de canais como o telégrafo, filme, rádio, televisão e internet), trouxe consigo novos modelos informacionais e permitiu a convergência de linguagens e mídias. Este último estágio da cultura elétrica, no qual ocorreu o boom dos computadores e da internet, faz surgir o que Jenkins (2008) denominou de cultura da convergência, que consiste em possibilitar que o conteúdo seja trabalhado em diferentes fluxos, pelos mais diversos meios, que atuam de forma cooperativa na produção de sentido. Diante deste contexto, a fruição ${ }^{3}$ do conteúdo pode ser feita pelos mais diferentes caminhos. Para Jenkins, esta nova cultura exige uma alquimia para trabalhar, de forma concomitante, novas e antigas mídias, colocando abaixo a perspectiva da caixa preta que iria substituir todos os meios, pois traria todas as suas funcionalidades. O erro nesta acepção foi focar na transformação tecnológica, esquecendo a cultural, que se estabelece por trás de mudanças como as que foram vivenciadas. Ainda, segundo o autor, o obsoleto não está nos meios de comunicação, mas apenas nos meios de distribuição: "As palavras impressas não eliminaram as palavras faladas. O cinema não eliminou o teatro. A televisão não eliminou o rádio" (JENKINS, 2008, p. 39).

\footnotetext{
${ }^{2}$ Uma versão deste artigo intitulada "Design Thinking como abordagem metodológica para análise de produções jornalísticas em sites de redes sociais" foi publicada nos Anais do $41^{\circ}$ Congresso Brasileiro de Ciências da Comunicação, realizado em Joinville - SC. Esta versão foi aprimorada a partir das ponderações dos integrantes do GP Comunicação e Cultura Digital.

${ }^{3}$ Aqui, entendida como o percurso realizado por meio de um fluxo imersivo eficaz.
} 
Tudo isso ocorre dentro de um panorama de agilidade nas mudanças tecnológicas vivenciadas, que sustentam a previsão da Lei de Moore ${ }^{4}$ (CASTELLS, 2003). Para os observadores científicos da contemporaneidade, a tarefa de empreender pesquisas se complexifica, tendo em vista que, muitas vezes, os aparatos empregados ao estudar estas mudanças e fenômenos não conseguem acompanhar a velocidade das alterações. Por isso, o trabalho dos investigadores envolve a atenção constante e a incessante busca por diferentes abordagens metodológicas que possam contribuir com a pesquisa das inovações que surgem ao longo da trajetória da humanidade.

Do ponto de vista do jornalismo, a velocidade das mudanças, cada dia mais célere nesta hipermodernidade ${ }^{5}$, desafia os jornalistas que atuam nos meios a compreender estas novas concepções, muitas vezes, em tentativas que geram erros e acertos, para dar conta da produção exigida e do interesse multifacetado e conectado de interagentes ${ }^{6}$, cada vez mais instáveis.

A combinação da mobilidade da internet criou um novo paradigma da leveza, inscrito sob o signo do nomadismo digital. Não é mais exclusivamente o domínio estético que é o lugar da leveza positiva, mas a hipermobilidade, o "borboletear", a fluidez de navegação sobre as redes virtuais (LIPOVETSKY, 2016, p. 127).

Considerando todos estes aspectos, o presente artigo tem como objetivo propor um modelo de aproximação da abordagem de pesquisa do Design Thinking com a área de Jornalismo. Para isso, o artigo traz um piloto $^{7}$ de percurso de análise que utiliza de ferramentas do Design Thinking, como a jornada do usuário e o mapa da empatia, para

\footnotetext{
${ }^{4}$ A Lei foi baseada em uma projeção feita por Gordon Earl Moore, proprietário da Intel, em 1965. Ele afirmou que o poder de processamento dos computadores dobraria a cada 18 meses.

${ }^{5}$ Baseia-se, aqui, na apreensão de Gilles Lipovetsky (2016) do tempo presente, que, também, pode ser definido de outras maneiras. Bauman chama de "pós-modernidade", Anthony Giddens de "modernidade tardia" e Urich Beck de modernidade reflexiva. Para Lipovetsky, na hipermodernidade, a vida individual e coletiva tende ao leve, efêmero e ao mudancismo. Constitui-se um "individualismo de tipo nômade e zapeador" (2011, p. 22). Bauman (2011, p. 25), que inspira Lipovetsky, afirma que a atual sociedade é marcada por laços eletrônicos, que são criados para "apagar, reescrever e escrever por cima". Nessa era, os consumidores, inclusive do Jornalismo, anseiam ainda mais pela novidade e que ela seja breve ou facilmente substituível, tendo em vista que quase não há mais espaço para a perenidade em suas vidas.

${ }^{6}$ Neste artigo, oscila-se entre as denominações "interagente" e usuário. Sabe-se da proposta de Alex Primo (2005, p. 2), que ao analisar interação mediada por computador, conclui que "interagente" é o termo mais adequado visto que: "O termo 'usuário', tão utilizado nos estudos da 'interatividade', deixa subentendido que tal figura está à mercê de alguém hierarquicamente superior, que coloca um pacote a sua disposição para uso (segundo as regras que determina). Isso posto, este trabalho defende o abandono desse problemático conceito e preferirá adotar o termo 'interagente' (uma tradução livre de interactant, não raro utilizado em pesquisas de comunicação interpessoal), que emana a própria idéia de interação". No entanto, nos estudos de Design Thinking, oriundos da área do design, é comum a utilização da palavra usuário para se referir a este indivíduo. Portanto, aqui, alterna-se entre estas nomenclaturas, até pelo caráter interdisciplinar da proposta.

${ }^{7}$ Ressalta-se que este é um modelo inicial, que ainda precisaria de aplicação em uma escala maior para trazer resultados conclusivos.
} 
investigar narrativas jornalísticas inovadoras, tendo como corpus postagens produzidas por veículo jornalístico para as Stories do Instagram. Para dar conta desta proposta, o artigo conta com quatro secções. Na primeira, explica-se de que forma as inovações desafiam a área de jornalismo e cobram novas propostas metodológicas para serem compreendidas. Em seguida, dedica-se a explicitar a abordagem do Design Thinking e a adequação de suas ferramentas para o desenvolvimento de pesquisas em Jornalismo. A terceira secção demonstra, a partir das ferramentas jornada do usuário e mapa da empatia, uma proposta piloto de aplicabilidade. Por fim, elencam-se as considerações parciais deste modelo experimental proposto. Pretende-se,

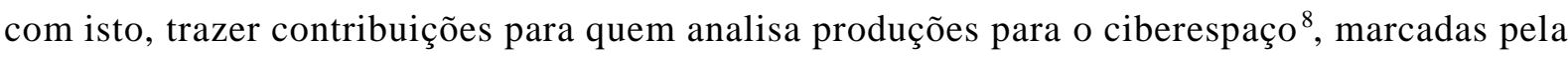
centralidade no usuário.

\section{INOVAÇÃO NO JORNALISMO}

A inovação não necessariamente é algo inédito. O que é inovador para um indivíduo pode não ser para outro. Como aponta Marcio Carneiro (2016), uma inovação é uma ideia nova para quem toma ciência dela, ainda que não seja nova para outras pessoas. Por isso, Rogers (2003) ressalta que em um processo de difusão de uma inovação existem quatro elementos fundamentais: a inovação, os canais de comunicação, o tempo e o sistema social. É a partir da divulgação da inovação pelos canais de comunicação que se inicia a disseminação.

Para Marcio Carneiro (2016), existem dois modos de adoção de uma inovação. O primeiro é quando um determinado número de outras pessoas da rede também o fazem, ou seja, é necessário chegar a um limite ou limiar (threshold) para que a adesão aconteça. E o segundo é conhecido como aprendizado social, que é quando as pessoas adotam por verem evidências suficientes, entre adotantes anteriores, que as convencem de que a inovação é interessante.

Do ponto de vista conceitual, é preciso ter cautela no uso da palavra inovação, principalmente agora, já que ela vem sendo empregada com frequência em vários ambientes e contextos, o que pode diluir o seu valor e potencial teórico. Como bem propõe Thomas M. Koulopoulos (2011, p. 59):

\footnotetext{
${ }^{8}$ Para Sterling, o ciberespaço já existe há mais de um século e é considerado um "lugar". "Ciberespaço é o 'lugar' onde a conversação telefônica parece ocorrer. (...) O lugar indefinido fora daqui, onde dois de vocês, dois seres humanos, realmente se encontram e se comunicam. [...] Apesar de não ser exatamente 'real', o 'ciberespaço' é um lugar genuíno. Coisas acontecem lá e têm consequências muito genuínas. (...) Ciberespaço é hoje uma 'Rede', uma 'Matriz', internacional no escopo e crescendo rapidamente e constantemente" (STERLING apud KIM, 2004, p. 213). Esta posição vai ao encontro do que ponderou Pierre Levy, ao demarcar que o virtual não se opõe ao real, mas ao atual. A virtualização, para ele, é o inverso da atualização e não uma desrealização. "A imaginação, a memória, o conhecimento, a religião são vetores de virtualização que nos fizeram abandonar a presença muito antes da informatização e das redes sociais” (LEVY, 1996, p. 20).
} 
A inovação precisa ser um sistema: trata-se de um processo para se tornar inovador, e não para simplesmente inventar um produto específico. Embora os produtos tenham dominado a nossa noção de inovação, o valor duradouro é criado por meio de um novo modelo de negócios, capaz de recombinar as ideias e invenções já existentes e criar um novo valor.

Isso quer dizer que inovação não deve ser confundida com um novo produto, ou uma nova tecnologia, embora esta possa sim vir a ser inovadora. A inovação pode estar relacionada às mudanças processuais que otimizem uma prática dentro de uma organização, por exemplo. Para Franciscato (2010), no Jornalismo, a inovação pode ser percebida em três dimensões: tecnológica, organizacional e social.

A inovação tecnológica no jornalismo, portanto, não pode ser considerada como um investimento isolado em modernização industrial, mas caracterizada também como um aporte que modifica as rotinas e processos de trabalho do jornalista, bem como o perfil e a qualidade do produto jornalístico (FRANCISCATO, 2010, p. 12).

Já a inovação organizacional se distingue desta primeira por ter um caráter interativo formal entre pessoas. Consiste em alterações nas relações de autoridade, na remuneração por determinada atividade, nos sistemas comunicativos etc. Por fim, a inovação social, também, é bastante distinta da tecnológica. Nela, há a ideia de desenvolvimento social. A inovação social foca nos efeitos sociais dos processos interativos, ou seja, nas interações dos agentes sociais nas organizações jornalísticas (FRANCISCATO, 2010). Sobre inovação social, André e Abreu (2006, p. 125) também ressaltam que ela tem "uma natureza não mercantil, um carácter colectivo e uma intenção que não só gera, mas também visa, transformações das relações sociais".

Vale destacar que tais inovações não precisam ocorrer de forma isolada. Por vezes, um incremento tecnológico pode dar margem às mudanças que configuram uma inovação organizacional. O computador e a internet, são exemplos disso, possibilitaram o surgimento da cultura de convergência, modificaram rotinas (produção de conteúdos multimídia, mesmo por equipes de jornais impressos, por exemplo; veículos passam a se preocupar com as atualizações de seus perfis em plataformas de redes sociais ${ }^{9}$ ), novas funções foram criadas dentro das redações (tais como gerente de conteúdo multimídia, redator multimídia etc.), e

\footnotetext{
${ }^{9}$ Segundo Boyd e Elisson (2013, p. 74), sites de redes sociais (SRS) são: “uma plataforma de comunicação em rede na qual os participantes 1) possuem perfis identificáveis de forma exclusiva que consistem em conteúdo fornecido pelo usuário, conteúdo fornecido por outros usuários e/ou dados fornecidos pelo sistema; 2) podem articular publicamente conexões que podem ser vistas e percorridas por outros; e 3) podem consumir, produzir e/ou interagir com fluxos de conteúdo gerados pelo usuário e fornecidos por suas conexões no site".
} 
permitiram o desenvolvimento de uma cultura participativa, transformando as relações sociais entre os jornalistas e os cidadãos. Surge a "citizen media", ou "mídia do cidadão", como alcunhou André Lemos, ao pesquisar sobre a cibercultura ${ }^{10}$. A "citezen media" é fruto do trabalho do indivíduo não jornalista que passa criar, colar, mesclar, reciclar e compartilhar conteúdos digitais, sejam em áudio, vídeo, texto ou fotos (LEMOS, 2005).

Neste artigo, foca-se em uma inovação tecnológica, que é nativa deste contexto de ebulição da cultura da convergência e da cultura participativa, e foi assimilada pelo jornalismo nos últimos tempos: os conteúdos produzidos para as Stories do Instagram. O surgimento e a popularização do Snapchat fizeram com que outras plataformas de redes sociais adotassem ferramentas com mecanismos semelhantes para a produção de conteúdo. Em agosto de 2016, o Instagram, plataforma de rede social de fotos e vídeos do Facebook, lançou as Stories, um recurso dentro do aplicativo para a criação de postagens que ficam disponíveis por no máximo 24 horas, assim como no Snapchat. O Instagram Stories é muito semelhante ao Minha História, do Snapchat, sendo possível até personalizar as postagens com desenhos, textos, adesivos e filtros em realidade aumentada, como no concorrente.

As redações jornalísticas, que já haviam assimilado que teriam que estar presentes nestas plataformas para conseguirem atingir os seus públicos-alvo, tiveram que se adaptar a essa nova ferramenta de produção de conteúdo, que subverte um aspecto que, até então, era caro ao jornalismo: o arquivamento de memórias.

A preocupação deixa de ser documentação e compartilhamento de conteúdo jornalístico em álbuns virtuais e passa a ser como produzir um conteúdo que marque o interagente, ainda que seja mais fragmentado (de 10 em 10 segundos), ágil (de atualização constante e contínua) e que se autodestrói depois das $24 \mathrm{~h}$. Isso subverte a lógica estabelecida pela potencialidade da internet inicialmente, que era a de armazenamento infinito do conteúdo produzido pelos interagentes. A internet permitiu uma acumulação maior de informações, mas, também, que isto fosse feito com melhor viabilidade técnica e econômica. Conforme destaca Marcos Palácios (p. 6) ${ }^{11}$,

[...] a Memória no Jornalismo na Web pode ser recuperada tanto pelo Produtor da informação, quanto pelo Utente, através de arquivos online providos com motores de busca (search engines) que permitem múltiplos

\footnotetext{
${ }^{10}$ Para Kim (2004), trata-se de uma cultura que se desenvolve a partir do modelo científico da cibernética, que não se sustenta, mas deixa resquícios como valores oriundos do discurso técnico e científico, que são absorvidos pelo senso comum. "Um dos resíduos mais importantes que a cibernética legou à cibercultura foi a visão de que os seres vivos e as máquinas não são essencialmente diferentes" (2004, p. 206).

${ }^{11}$ Arquivo não datado.
} 
cruzamentos de palavras-chaves e datas (indexação). Sem limitações de espaço, numa situação de extrema rapidez de acesso e alimentação (Instantaneidade e Interactividade) e de grande flexibilidade combinatória (Hipertextualidade), o Jornalismo tem na Web a sua primeira forma de Memória Múltipla, Instantânea e Cumulativa.

Considerando o impacto desta modificação para a área de jornalismo, acredita-se que o Design Thinking pode fornecer ferramentas que ajudem na tarefa de otimizar o conteúdo produzidos para plataformas que produzam conteúdos nos moldes aqui descritos, partindo da experiência do usuário para definir melhor suas estratégias. Por apresentar ferramentas metodológicas que, em algum momento, visam a aplicabilidade, via prototipação, o Design Thinking pode ser um eficiente aliado nesse processo de incessantes mudanças vivenciado pelo Jornalismo, ajudando, no caso descrito aqui, a potencializar a relação entre este tipo de conteúdo jornalístico e a constituição de uma memória informativa no usuário. Para entender como esta articulação pode ser eficiente, é preciso, primeiro, compreender o seu modo de funcionamento desta abordagem.

\section{DESIGN THINKING}

Como o próprio nome sugere, Design Thinking consiste num modo peculiar de pensar da área do design, mas que não se restringe a ela. Trata-se de uma abordagem metodológica focada em buscar soluções para problemas que afligem o cotidiano das pessoas. Conforme explica Tim Brown (2008, p. 3), é “... uma metodologia que permeia todo o espectro de atividades de inovação com uma filosofia de design voltada para pessoas"

Com o objetivo de transformar a experiência do indivíduo em algo mais prazeroso, o Design Thinking parte do usuário para elaborar propostas e protótipos. Ao atingir o objetivo inicial, reverte a estratégia desenvolvida em uma oportunidade de mercado, de forma a conseguir, inclusive, viabilizá-la.

Em termos simples, é uma disciplina que usa sensibilidade e os métodos do designer para atender às necessidades das pessoas com o que é tecnologicamente viável e com uma estratégia de negócios viável que pode se transformar em valor para o cliente e uma oportunidade de mercado (BROWN, 2008, p. 4) ${ }^{13}$.

\footnotetext{
${ }^{12}$ Tradução de: "uma metodologia que impregna todo el espectro de atividades de innovación con uma filosofia de diseño centrada em las personas" (BROWN, 2008, p. 3).

${ }^{13}$ Tradução de: "En términos sencillos, es una disciplina que usa la sensibilidad y los métodos del diseñador para hacer coincidir las necesidades de las personas con lo que es tecnológicamente factible e con lo que una estrategia viable de negocios puede convertir en valor para el cliente y en una oportunidad de mercado" (BROWN, 2008, p. 4).
} 
Segundo essa abordagem, deve-se buscar algumas virtudes nos chamados pensadores de desenho (los pensadores de diseño), dentre as quais: empatia, para conseguir estar nas mais diferentes situações e entendê-las a partir de tal vivência; pensamento integrador, ao ser capaz de ver o todo; otimismo, por considerar sempre que existe pelo menos uma alternativa para dado problema; experimentalismo, para buscar uma direção nova para resolver a situação; e colaboração, que consiste em saber trabalhar com profissionais de diversas áreas (BROWN, 2008). Após desenvolver em si todas estas características, vem o momento de pensar os projetos, que atravessam três etapas.

Em última análise, os projetos de design devem passar por três momentos (...) Os rotulamos como "inspiração", pelas circunstâncias (seja um problema, uma oportunidade ou ambos) que motivam a busca de soluções; "ideação", pelo processo de geração, desenvolvimento e teste de idéias que podem levar a soluções; e "implementação", traçando uma rota até o mercado. Os projetos retornarão através desses espaços - especialmente os primeiros - mais de uma vez, à medida que as ideias forem refinadas e novas direções forem tomadas (BROWN, 2008, p.7) ${ }^{14}$.

Ao escolher como abordagem o Design Thinking, é preciso ter em mente que a solução para o problema analisado pode não surgir em um primeiro momento. Por isso, são importantes os testes de aplicabilidade das possíveis soluções. Examinar as ideias, observar seus funcionamentos, buscar os pontos fracos a serem melhorados, são algumas das tarefas ao longo desses três momentos que compõem a abordagem metodológica. Ao final, deve-se chegar a uma solução viável e atrativa para o usuário, tendo em vista que "O bom design, satisfaz nossas necessidades e nossos desejos" (BROWN, 2008, p. 10) ${ }^{15}$.

Basicamente, é preciso entender como um designer pensa, compreendendo o que ele faz e como ele o faz. O designer é o indivíduo que transforma um briefing em um produto ou solução de design, seja por fins econômicos ou criativos. Para atingir seu objetivo, vai atravessar sete etapas, ao longo do trabalho: definir, pesquisar, gerar ideias, testar protótipos, selecionar, implementar e aprender. "Cada etapa exige o design thinking, um modo de pensar o projeto voltado para o seu usuário" (AMBROSE; HARRIS, 2011, p. 10).

\footnotetext{
14 Tradução de: "En última instancia, los proyectos de diseño deben pasar por tres espacios (...) Etiquetamos éstos como ‘inspiración', por las circunstancias (ya sean un problema, una oportunidad o ambas cosas) que motivan la búsqueda de soluciones; 'ideación' por el proceso de generar, desarollar y probar ideas que pueden conducir a soluciones; e 'implementación', por el trazado de una ruta al mercado. Los proyetos retornarán a través de estos espacios - especialmente a los primeiros - más de una vez, a medida que se perfeccionan las ideas y se toman nuevas direcciones" (BROWN, 2008, p. 7).

15 Tradução de: "En buen diseño satisface tanto nuestras necesidades como nuestros deseos" (BROWN, 2008, p. 10).
} 
O ponto de início é o briefing, que vai orientar as demais etapas, visto que consiste no diagnóstico das necessidades, potencialidades e solicitações que envolvem dado projeto. "Ele pode ser verbal ou escrito; simples ou complexo; contém um objetivo específico que deve ser atingido pelo design, mas também pode ser formulado de maneira a possibilitar diversas interpretações" (AMBROSE; HARRIS, 2011, p. 13).

O briefing é a base para os processos de inspiração, ideação e implementação, pois abastece com as informações necessárias os profissionais que estarão engajados na busca por soluções. Neste momento, o Design Thinking se assemelha ao Jornalismo, pois o briefing é uma ferramenta comum nas assessorias de comunicação, que ajuda a pensar estratégias de comunicação interna e externa das organizações. Da mesma forma, nesta abordagem oriunda do design, ele responde algumas perguntas básicas que ajudarão a nortear o trabalho.

As cinco perguntas básicas do texto jornalístico podem ser empregadas no
design para que se extraiam respostas factuais necessárias à definição
adequada do projeto de design. São elas: quem, o que, quando, onde e por
que (o "como" também aparece com frequência entre as perguntas).
Indagações como essas fornecem informações que a equipe de design pode
utilizar ao longo de todo o processo do projeto, além de identificarem as
principais limitações que precisam ser contornadas (AMBROSE; HARRIS,
2011, p. 15).

Desta parte em diante, serão desenvolvidas propostas e soluções, nisto consiste a fase de inspiração e ideação, marcada por processos de geração de ideias, brainstorm, esboço ou rafe (rough). As propostas apresentadas devem estar atreladas às ideias e valores que se objetiva fortalecer no público-alvo, evitando divagações inúteis. Na etapa seguinte, elaboramse os protótipos. A prototipação é de fundamental importância, pois, permitirá testar a eficácia e viabilidade da solução proposta. "Por meio dos protótipos, a equipe e o cliente conseguem visualizar e manusear um conceito de design, tendo uma ideia de sua presença física e de suas qualidades táteis" (AMBROSE; HARRIS, 2011, p. 21). Implementa-se, então, a solução que se adequar melhor às necessidades que foram apontadas lá no briefing, considerando como pontos de avaliação fatores como custo e tempo.

Após a implementação, o cliente já pode começar a buscar ou receber um retorno sobre como o produto foi recebido e quais foram seus efeitos sobre o público-alvo, e assim a empresa de design pode saber como o consumidor respondeu à solução de design proposta. O feedback gerado no final do processo torna-se uma oportunidade de aprendizado para futuros projetos (AMBROSE; HARRIS, 2011, p. 27). 
Vale ressaltar que essas três últimas etapas (ideação, prototipação e implementação) podem ser realizadas diversas vezes, até que o objetivo primeiro do projeto, apontado no briefing, seja alcançado. O importante é que, terminados todos os processos, tenha-se uma solução que pense no usuário, do início ao fim. Ou seja, que o objetivo atingido traga soluções relevantes para o público-alvo.

Dentre as várias ferramentas utilizadas pelo Design Thinking na busca por soluções, estão: observação, entrevista, netnografia, jornada do usuário, storytelling, enquadramento, testes com usuários, captura de feedback, mapa de empatia etc. Aqui, o foco será em duas ferramentas que podem permitir percepções relevantes em pesquisas sobre a produção jornalística feita para o ciberespaço: a jornada do usuário e o mapa da empatia. Trata-se de um esboço de aplicabilidade destas ferramentas, de forma a exemplificar modos de utilização para pesquisas na área.

Selecionou-se a jornada do usuário e o mapa da empatia por permitirem um aprofundamento nos conhecimentos acerca dos altos e baixos experienciados pelo usuário, ao vivenciar algo em dado ambiente. Aqui, a diferença é que tal ambiente é digital, pode ser um portal jornalístico, um site de rede social etc. Melo e Abelheira (2015, p. 63), ao tratarem sobre a jornada do usuário, destacam que: "É uma ferramenta que tem diversas aplicações, mas é mais usada em serviços de uma maneira geral, ou literalmente para avaliar experiências que podem ser descritas como eventos ao longo de uma linha do tempo". É importante frisar que esta linha temporal não é fixada de forma rígida, pode ser de horas, dias, meses e anos, dependendo de cada objetivo e projeto. Associado a um mapa de empatia, que detalha as emoções e sentimentos do usuário no momento de navegação e encontro com um produto, pode trazer informações esclarecedoras para a otimização de processos e produtos, gerando assim inovação para a área. O mapa de empatia consiste em

uma ferramenta de síntese das informações sobre o cliente numa visualização sobre o que ele diz, faz, pensa e sente. Assim, possibilita a organização dos dados da fase de imersão de forma a prover entendimento de situações de contexto, comportamentos, preocupações e até aspirações do usuário (VIANNA et all, 2012, p. 83).

Ao colocar em prática o mapa da empatia, deve-se criar um diagrama que organize seis áreas, estando ao centro o usuário. As áreas destacadas devem responder aos seguintes questionamentos: $\mathrm{O}$ que o usuário enxerga? $\mathrm{O}$ que ouve? $\mathrm{O}$ que realmente pensa e sente? $\mathrm{O}$ que diz e faz? Quais são as suas dificuldades? E, por fim, quais são suas conquistas? A partir das respostas obtidas, cria-se um diagrama como poderá ser visto no próximo tópico. 


\section{DA APLICABILIDADE}

Neste tópico, será detalhado o modo de realização análise, por ser este o escopo do artigo, utilizando as ferramentas mencionadas anteriormente. Vale ressaltar que tais procedimentos foram aplicados com o intuito de compreender a percepção do usuário acerca do conteúdo jornalístico produzido para as Stories, tendo em vista relação entre este conteúdo jornalístico e a constituição de uma memória informativa. Parte-se desse objetivo para guiar as estratégias seguintes.

O primeiro passo foi chegar ao usuário analisado. Buscou-se o público da plataforma de Redes Sociais que interessava, no caso Instagram, mais especificamente que fizessem uso das Stories. Segundo dados divulgados pelo Instagram, o público feminino é predominante. Mulheres representam $61 \%$ e homens 38\%. Quanto à faixa etária, no Instagram, maior parte do público se concentra entre os 18 e os 25 anos. A partir destas informações, delimitou-se que o usuário deveria se identificar com o gênero feminino e ter entre 18 e 24 anos, por estar no grupo de maior concentração de público. Como este artigo objetiva apenas realizar uma exemplificação metodológica estes foram os únicos critérios se seleção. Para além deste artigo, frise-se que a seleção deve concentrar uma amostra de usuários mais abrangente em número e perfis, sendo equivalente ao público das plataformas analisados. Este foi apenas um recorte estabelecido para este artigo a título de demonstração da aplicabilidade da proposta.

\section{a) A usuária}

A pessoa selecionada ${ }^{16}$ será identificada como Maria ${ }^{17}$, é jornalista e tem 24 anos. Ela nasceu na cidade de Itaqui-RS e, atualmente, mora em Florianópolis-SC, onde trabalha em uma empresa de comunicação e Marketing, área em que tem uma pós-graduação. Com isso, percebe-se que a interagente tem um bom nível educacional e é consumidora de notícias em diversas mídias, dada a profissão de atuação. Economicamente, pode-se enquadrá-la na classe C, segundo divisão do Instituto Brasileiro de Geografia e Estatística (IBGE) ${ }^{18}$.

Maria é usuária do Instagram e segue o perfil do Gl nesta plataforma. Por trabalhar na área, ela não só consome notícias pelo Instagram, como, também, está acostumada a produzir conteúdo para o Instagram, incluindo jornalístico. O consumo de notícias dela,

\footnotetext{
${ }^{16}$ A seleção foi feita por conveniência e considerando como norte o perfil de usuários da plataforma já descrito. Trata-se de uma estudante que frequentou uma disciplina isolada no Programa de Pós-Graduação em Jornalismo da Universidade Federal de Santa Catarina (UFSC), da qual a autora do artigo faz parte como discente.

${ }^{17}$ Nome fictício.

${ }^{18}$ Renda familiar de $\mathrm{R} \$ 3.748,01$ a $\mathrm{R} \$ 9.370,00$.
} 
diariamente, é intenso, por causa da rotina de trabalho. Além das plataformas de redes sociais, ela consome notícias via website, assina a versão on-line do jornal Diário Catarinense (DC) e utiliza o Google News, que permite selecionar áreas de interesse para receber notícias segmentadas. Ou seja, apresenta familiaridade com as plataformas de redes sociais, com notícias produzidas para estes ambientes, bem como, facilidade em lidar com tecnologia.

Especificamente no Instagram, ela aponta que costuma a consumir mais os conteúdos que são produzidos para as Stories, do que os que são disponibilizados na linha do tempo das postagens que perduram. "Quando fazem vídeo! Quando colocam só fotos não chama muito a minha atenção. Quando colocam link para alguma página, que permita ter alguma interação com aquele conteúdo me interessa mais", frisou Maria em entrevista. Ela afirma, ainda, gostar da disponibilização de enquetes (ferramenta possível) e testes (que, normalmente, são acessados via link, embora a ferramenta recentemente tenha incorporado esta função). Com estas e outras informações fornecidas via entrevista, construiu-se o seguinte mapa da empatia:

Figura 1: Mapa da empatia de Maria

Nome: Maria Idade: 24 anos

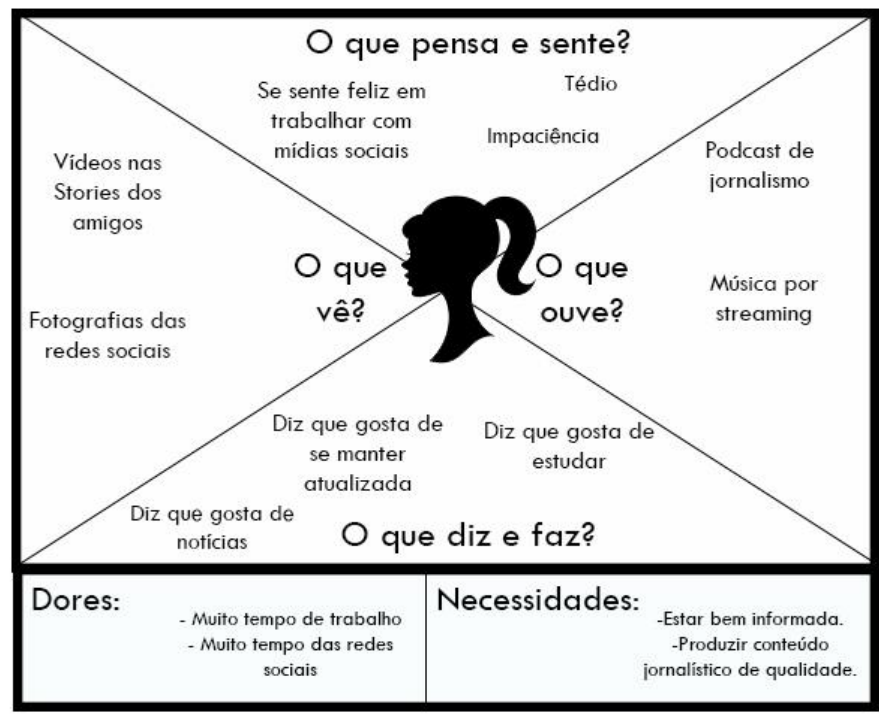

Fonte: elaborada pela autora

Percebe-se que Maria concilia muitas atividades quando faz uso do aparelho celular. A atividade proposta de consumir notícias produzidas para as Stories, por exemplo, acaba sendo realizada em meio a outras como ouvir músicas e podcasts em aplicativos de streaming, produzir conteúdos para as empresas clientes no seu trabalho etc. Ao mesmo tempo, percebese que essa rotina múltipla faz com que Maria consuma notícias pelos mais diversos meios, estando acostumada com diferentes formatos. Além disso, seu consumo de notícias é intenso 
o que exige do conteúdo jornalístico um diferencial para que este marque a usuária e não passe despercebido em meio a outros. Tendo todos estes aspectos em mente, parte-se, então, para a reconstrução da jornada da Maria no consumo de uma notícia produzida pelo perfil do G1 para as Stories do Instagram.

\section{b) A jornada da maria}

Para analisar a jornada da Maria, primeiro, instalou-se no celular dela um aplicativo de gravação de tela ${ }^{19}$. Assim, toda a movimentação realizada por ela, ao utilizar o Instagram e, mais especificamente, as notícias produzidas para as Stories, poderia ser monitorada, analisada e revisada posteriormente.

Em seguida, pediu-se que ela realizasse o Figura 2: Print de um post do G1 nas Stories do Instagram consumo de um dia de produção de postagens do Gl. Este veículo de comunicação não realiza postagens diariamente, por isso, aguardou-se até uma data em que houve atualizações nas Stories do perfil do G1. Isto ocorreu na data do casamento do príncipe Harry com a atriz Meghan Markle, no dia 19 de maio de 2018. Portanto, todas as postagens realizadas foram destinadas à cobertura do casamento.

Aqui, como dito anteriormente, o foco será em utilizar a jornada do usuário para perceber a relação entre este conteúdo jornalístico e a constituição de uma memória informativa. Dessa forma, a entrevista realizada com a Maria, bem como o monitoramento da navegação dela no Instagram, foi voltada, especificamente, para apreender aspectos da

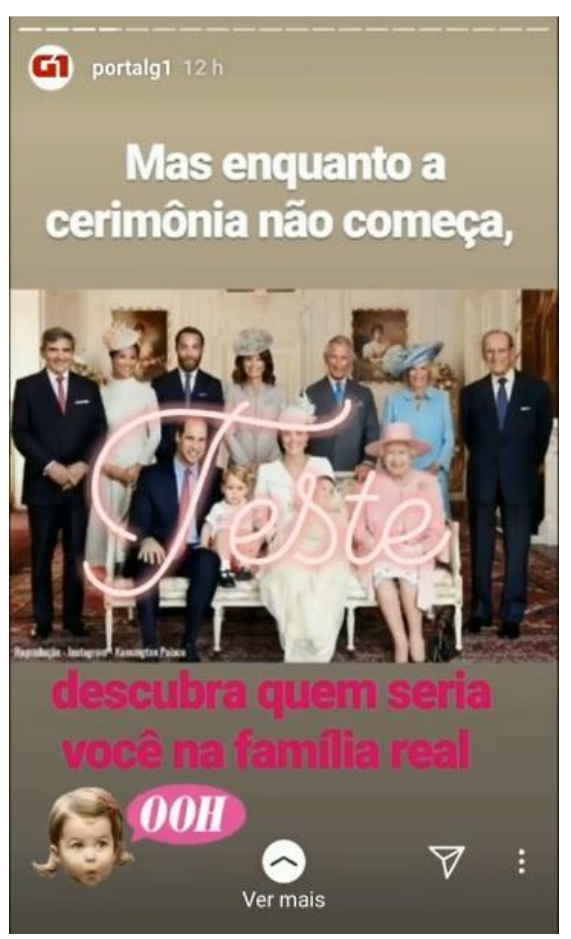

Fonte: Stories do portal G1 memorização do conteúdo produzido.

Quanto às postagens do $G 1$, elas remetiam a conteúdos diversos do site. Todas as Stories traziam links para as diferentes matérias do portal. As postagens se alternavam entre chamadas para estes conteúdos, brincadeiras e curiosidades. Não foram utilizados vídeos. Em

${ }^{19} \mathrm{O}$ aplicativo de gravação de tela escolhido foi o Record it! 
termos de elementos visuais, foram observados: fotos; tipografias especiais, como manuscritas e decorativas; GIFs e emojis. A Story ao lado traz boa parte destes elementos.

Ao observar a jornada gravada, percebe-se que a Maria começa utilizando os dez segundos de cada postagem para a fruição do conteúdo. Isso ocorre nas quatro primeiras postagens. A quarta postagem (da imagem anterior) faz uma chamada para um teste. Maria acessa o link para realizar o teste. Ela passa um minuto e 18 segundos respondendo-o. Ao final, não chega a ler a resposta toda, apenas identifica o seu resultado e lê as primeiras informações. Ela volta novamente para as postagens do $G 1$ nas Stories do Instagram, nesta retomada, já não passa mais os dez segundos consumindo. A atenção dela varia entre um e cinco segundos, dependendo da postagem. Ao todo, foram 20 postagens criadas pelo $G 1$ sobre o casamento.

Como o objetivo era identificar aspectos relativos à memorização do conteúdo produzido, realizou-se a entrevista com a Maria uma semana depois da gravação, no dia 26 de maio de 2018. Assim, poderiam ser identificados os elementos que ela conseguia se lembrar, mesmo tendo passado um curto período de fruição do conteúdo.

Transcorrido este tempo, Maria conseguia se lembrar do tema geral das postagens vistas (Casamento Real) e de aspectos genéricos das informações. Ela afirmou que o conteúdo não era muito noticioso e, sim, de entretenimento. Nesse momento, expressa um pouco de tédio, como se aquele enfoque não fosse o mais interessante para ela (isso está representado no mapa da

Figura 3: Jornada da usuária gravada

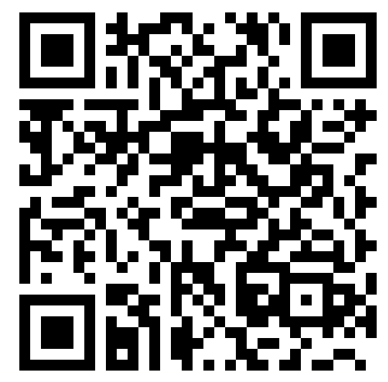

Fonte: Entrevista elaborada pela autora empatia). "Era tipo: tal pessoa estava se vestindo de tal maneira. Tinha até um teste: saiba quem você é na Família Real", relembrou. Questionada sobre o resultado do teste respondido, ela disse não se lembrar.

Sobre os aspectos visuais, a entrevistada afirmou lembrar de imagens, mas não saber definir se as imagens que vinham em suas lembranças eram as que estevam no perfil do $G 1$ ou em outro veículo de comunicação que tratou do mesmo assunto, naquele dia. Quando questionada se gostava de elementos visuais no geral, e não especificamente daquelas que estavam na postagem (visto que ela não se lembrava), ela disse que "sim", mas sentia que, muitas vezes, a atenção dela se voltava muito para eles e pouco para a informação principal da postagem. 
Articulando a gravação com a entrevista da usuária, pode-se chegar a algumas conclusões no que tange a memorização do conteúdo. Primeiramente, é possível perceber que mesmo algum tempo depois, a temática das postagens ainda estava fixada na memória de Maria, bem como o fato de que, dentre as postagens, havia um conteúdo diferenciado, mais lúdico e interativo, que era o teste. No entanto, as informações mais específicas foram perdidas. Ela não consegue fazer uma associação visual com segurança sobre as postagens e, também, não aponta nenhuma especificidade sobre as informações disponibilizadas, sequer o resultado do teste que chamou tanto a atenção dela.

Um fator pode ter colaborado para a dificuldade de memorização: a passagem rápida pelas Stories. Na maioria delas, Maria não usou nem a metade do tempo disponível observando e lendo o que estava escrito. Esta rapidez, identificou-se na entrevista, que, em parte, foi pelo baixo teor informativo das postagens, que se concentravam mais em brincadeiras e menos em informações relevantes para o usuário, e, por outro lado, foi pela avidez em consumir outros conteúdos, disponíveis nos variados perfis seguidos pela interagente, tanto de amigos, quanto de veículos de comunicação. Conseguiu-se, com isso, observar alguns problemas a serem resolvidos com relação ao conteúdo jornalístico produzido. Com tais problemas definidos e devidamente pesquisados, passa-se para os momentos de inspiração e ideação, nos quais serão propostas soluções.

Para servir de base para estes momentos, alguns caminhos foram apontados pela própria Maria como modos de conseguir que ela fixe mais a atenção e, assim, consiga a formação de uma memória informativa, mesmo com conteúdos ágeis e autodestrutivos, como os analisados aqui. O primeiro deles é o cuidado no uso de elementos visuais, estas plataformas possibilitam muitos recursos visuais (emojis, adesivos, GIFs, filtros em realidade aumentada etc), é importante que se utilize estes elementos de uma forma que eles atraiam a atenção do usuário, mas não a ponto de dispersá-lo da informação principal. Trata-se de um desafio de design. Além disso, a Maria apontou ter preferência por vídeos e gostar muito de vídeos em que os jornalistas aparecem transmitindo ou explicando as notícias. Trazer o jornalista para a tela do dispositivo móvel, por meio das ferramentas disponibilizadas por essas plataformas de redes sociais, pode ser um formato interessante a ser explorado, embora ele quase nunca seja visto no perfil do $G 1$.

Além disso, testes e enquetes são bem-vindos, mas não devem ser tão demorados e longos como o realizado por Maria. Ao final do teste, percebeu-se que ela sequer teve 
paciência para ler a resposta completamente com atenção, por isso, uma semana depois, já não tinha qualquer memória do resultado alcançado.

Seguindo a metodologia do Design Thinking, a partir desses procedimentos, seria criado um protótipo usando como referência as análises aqui empreendidas e os mesmos procedimentos seriam realizados para identificar se o protótipo criado é uma solução viável e que responde aos anseios de construção de uma memória informativa. Estas últimas etapas serão apenas mencionadas neste artigo, visto que o objetivo central é apenas explicar o passo a passo da metodologia proposta. É importante ressaltar que por este mesmo motivo, foi usado apenas um exemplo que contemplasse o mapa da empatia e a jornada do usuário. Sabese que isto não abrange o público-alvo das produções jornalísticas aqui analisadas e se entende que "É preciso pesquisar o público-alvo para que o design contenha os elementos necessários para uma boa comunicação com o consumidor" (AMBROSE; HARRIS, 2011, p. 34). Na prática, deveria ser feita uma amostra que estivesse em conformidade com os objetivos propostos no briefing. Esta amostra deve ser formada por um grupo de 5 a 10 pessoas, que se enquadrem no perfil do público-alvo, visto que deve ser representativa em termos de alguns atributos como idade, nível de escolaridade, etnia e características socioeconômicas (AMBROSE e HARRY, 2011). Aqui, não foram contempladas todas essas variáveis, ficando o artigo, também, restrito a apenas um caso, pois o foco era demonstrar didaticamente a aplicabilidade das ferramentas do Design Thinking para a análise de produções jornalísticas, por meio de um teste piloto.

\section{CONSIDERAÇÕES}

Conclui-se que o Design Thinking consiste em uma abordagem que propicia a inovação ao elaborar soluções testáveis. Com tal aplicabilidade, ao final do processo, o pesquisador pode escolher a solução mais adequada à realidade, considerando aspectos como recursos financeiros e estruturais, e tendo como diferencial o fato de que esta solução foi criada com o foco no usuário. O resultado é uma inovação centrada no humano, em suas necessidades e preferências, refletindo de forma mais aproximada os seus anseios (BROWN, 2008).

Com a construção do mapa da empatia da Maria, foi possível visualizar melhor quem é este público-alvo do conteúdo jornalístico produzido para as Stories do Instagram, o que faz e o que sente. Constituem esse público, pessoas como ela, classe média, consumidora ativa de 
notícias, que usa a plataforma tanto para o lazer quanto para o trabalho, que gosta de conteúdo audiovisual etc. Além disso, pôde-se mapear as emoções expressadas durante a entrevista, aliando-as às informações verbais, obtendo um diagnóstico mais completo das impressões da usuária acerca do conteúdo consumido.

Conhecendo um pouco mais da Maria e das emoções que perpassaram a experiência de consumo da informação jornalística, pôde-se dar continuidade à aplicação dos procedimentos metodológicos, elaborando estratégias que permitissem extrair resultados significativos, tendo em vista que o briefing inicial foca na retenção dessas informações jornalísticas pela memória do usuário.

Ainda que esta demonstração apareça, aqui, de forma bastante resumida, acredita-se que este piloto permite perceber o potencial da abordagem para trabalhar com produções que desafiem as rotinas jornalísticas no ambiente digital. A partir do diagnóstico obtido por meio das ferramentas do Design Thinking, pode-se, futuramente, elaborar uma proposta de conteúdo jornalístico inovador e que tenha apelo junto ao interagente, tornando-se competitivo diante deste cenário de inúmeras distrações por segundo. Inovar no jornalismo é um desafio, tendo em vista a alta velocidade das mudanças, mas, com ferramentas que auxiliem no processo de compreender as limitações, observar as potencialidades, inspirar e idear soluções testáveis e, por fim, implantá-las e propagar os conhecimentos obtidos pela implantação, acredita-se ser possível.

\section{REFERÊNCIAS}

ANDRÉ, Isabel; ABREU, Alexandre. Dimensões e espaços da inovação social. Disponível em: http://www.ceg.ul.pt/finisterra/numeros/200681/81_06.pdf. Acesso no dia 16 de julho de 2018. .

AMBROSE, Gavin; HARRIS, Paul. Design Thinking: s.m. ação ou prática de pensar o design. Porto Alegre: Bookman, 2011.

BAUMAN, Z. 44 cartas do mundo líquido moderno. Rio de Janeiro: Zahar, 2011.

BOYD, Danah M.; ELLISON, Nicole B. Sociality throught Social Network Sites. In: DUTTON, W. H. The Oxford Handbook of Internet Studies. Oxford: Oxford University Press, 2013 (pp. 151172).

BROWN, Tim. Design Thinking. Harvard Business Review. 2008. Disponível em: https://emprendedoresupa.files.wordpress.com/2010/08/p02_brown-design-thinking.pdf. Acesso em 10 de maio de 2018. 
BURKE, Peter. A Comunicação na história. In: RIBEIRO, A.P.G; HERSCHMANN, M. (Orgs). Comunicação e história: interfaces e novas abordagens. Rio de Janeiro: Mauad X; Globo Universidade, 2008.

CASTELLS, Manuel. A galáxia da Internet. Rio de Janeiro: Jorge Zahar, 2003.

FRANCISCATO, Carlos Eduardo. Uma proposta de incorporação dos estudos sobre inovação nas pesquisas em jornalismo. Revista Estudos em Jornalismo e Mídia. Ano VII, № 1, 2010.

JENKINS, Henry. Cultura da convergência. 2. ed. São Paulo: Aleph, 2009.

KIM, Joon Ho. Cibernética, ciborgues e ciberespaço: notas sobre as origens da cibernética e sua reinvenção cultural. Revista Horizontes Antropológicos. Porto Alegre, ano 10, 2004.

KOULOPOULOS, Thomas M. Inovação com resultado: o olhar além do óbvio. São Paulo: Editora Gente/Editora Senac, 2011.

LEMOS, André. Ciber-cultura-remix. 2005. [s.l.: s.n.]. Disponível em: https://facom.ufba.br/ciberpesquisa/andrelemos/remix.pdf. Acesso em 19 julho 2018.

LEVY, Pierre. O que é o virtual? São Paulo: Ed. 34, 1996.

LIPOVETSKY, Gilles. Da leveza: rumo a uma civilização sem peso. Barueri: Editora Manole, 2016

MELO, Adriana; ABELHEIRA, Ricardo. Design Thinking e Thinking...Design: metodologia, ferramentas e reflexões sobre o tema. São Paulo: Editora Novatec, 2015.

MARQUES DE MELO, José. História do Jornalismo: itinerário crítico, mosaico contextual. São Paulo: Paulus, 2012.

PRIMO, Alex. Enfoques e desfoques no estudo da interação mediada por computador. In: Laboratório de Interação Mediada por Computador (Limc), n. 45, 2005. Disponível em http://www.ufrgs.br/limc/PDFs/enfoques_desfoques.pdf. Acesso no dia 25 de junho de 2018.

ROGERS, Everett. Diffusion of innovations. Nova York: Free Press. 2003 [E-book]. Disponível em: $<$ http://www.amazon.com/Diffusion-Innovations-5th-Everett-

Rogersebook/dp/B000FC0NH8/ref=sr_1_1?s=digitaltext\&ie=UTF8\&qid=1391986181\&sr=11\&keyw ords=everett+rogers $>$. Acesso no dia 25 de março de 2019.

SANTOS, M. C. Comunicação Digital e Jornalismo de Inserção. São Luís: LABCOM DIGITAL, 2016.

VIANNA, Maurício; VIANNA, Ysmar; ADLER, Isabel K.; LUCENA, Brenda; RUSSO, Beatriz. Design Thinking: Inovação em Negócios. São Paulo: MJV Press, 2012. 
Bolsista Capes. Doutoranda do Programa de Pós-Graduação em Jornalismo, da Universidade Federal de Santa Catarina (UFSC), com estágio de Doutorado Sanduíche na Universidade de Aveiro (Portugal); mestre em Ciências Sociais, pela Universidade Federal do Maranhão (UFMA); e bacharel Jornalismo, também pela UFMA. Integrante do Grupo de Pesquisa em Telejornalismo (GipTele).

\section{Cárlida Emerim}

Jornalista, mestre em Semiótica, doutora em Processos Midiáticos, professora e pesquisadora na Graduação e Pós-Graduação de Jornalismo na Universidade Federal de Santa Catarina, líder do Grupo de Pesquisa em Telejornalismo (GipTele) e vice-coordenadora da Rede de Pesquisadores em Telejornalismo (Rede Telejor).

\section{@(๑)}

Esta obra está licenciado com uma Licença

Creative Commons Atribuição-NãoComercial-CompartilhaIgual 4.0 Internacional 